\title{
Predictive factors warrant screening for obstructive sleep apnea in COPD: a Taiwan National Survey
}

This article was published in the following Dove Press journal: International Journal of COPD

30 March 2016

Number of times this article has been viewed

\author{
Liang-Wen Hang, ${ }^{1,2}$ Jeng- \\ Yuan Hsu, ${ }^{3}$ Chee-Jen Chang, ${ }^{4}$ \\ Hao-Chien Wang, ${ }^{5,6}$ Shih-Lung \\ Cheng, ${ }^{7,8}$ Ching-Hsiung Lin, ${ }^{9}$ \\ Ming-Cheng Chan, ${ }^{3}$ Chin- \\ Chou Wang, ${ }^{10}$ Diahn-Warng \\ Perng, "' Chong-Jen $\mathrm{Yu}^{5,6}$ \\ On behalf of the Taiwan \\ COPD Consortium
}

'Department of Respiratory Therapy, College of Health Care, China Medical University, ${ }^{2}$ Sleep Medicine Center, Department of Pulmonary and Critical Care Medicine, China Medical University Hospital, ${ }^{3}$ Department of Internal Medicine, Taichung Veterans General Hospital, Taichung, ${ }^{4}$ Biostatistical Center for Clinical Research, Chang Gung Memorial Hospital, Linkou Branch, Guishan Township, Taoyuan County, ${ }^{5}$ Department of Internal Medicine, National Taiwan University Hospital, ${ }^{6}$ Department of Internal Medicine, National Taiwan University, College of Medicine, Taipei, ${ }^{7}$ Department of Internal Medicine, Far Eastern Memorial Hospital, New Taipei City, ${ }^{8}$ Department of Chemical Engineering and Materials Science, Yuan Ze University, Chung-Li City, Taoyuan County, ${ }^{9}$ Division of Chest Medicine, Changhua Christian Hospital, Changhua City, Changhua County, ${ }^{10}$ Division of Pulmonary and Critical Care Medicine, Kaohsiung Chang Gung Memorial Hospital, Kaohsiung, "Department of Chest Medicine, Taipei Veterans General Hospital, Taipei, Taiwan, Republic of China

Correspondence: Chong-Jen Yu Department of Internal Medicine, National Taiwan University Hospital, 7 ChungShan South Road, Taipei 100, Taiwan, Republic of China

Tel $+886223123456 \times 2905$

Fax +886223582867

Email jefferycjyu@ntu.edu.tw

Diahn-Warng Perng

Department of Chest Medicine, Taipei Veterans General Hospital, 20I, Section 2, Shi-Pai Road,

Taipei I I2, Taiwan, Republic of China

Tel +8862 287I 2I2Ix2078

Emaildwperng@vghtpe.gov.tw
Background and objectives: COPD and obstructive sleep apnea (OSA) share similar pathological processes and cardiovascular sequelae. Coexisting OSA in COPD - "overlap syndrome" - has worse prognosis than either condition alone, and appropriate treatment improves survival. Our objectives were to ascertain the frequency at which COPD coexists with the risk of OSA in Taiwan and to compare the risk factors, COPD symptoms, and life quality metrics between COPD subgroups with versus without risk of OSA.

Methods: We conducted a random cross-sectional national telephone survey of adults $>40$ years old in Taiwan. Participants fulfilling an epidemiological case definition of COPD completed a questionnaire to assess COPD symptoms and OSA risk, comorbidities, and performance of daily activities. Data from COPD cohorts with and without risk of OSA were analyzed and compared.

Results: Of 6,600 interviews completed, 404 subjects fit the epidemiological case definition of COPD - an overall prevalence of $6.1 \%$ in this national sample. Data on OSA risk were available for 292 of this COPD cohort, of whom 29.5\% were at risk of OSA. Compared to those without risk of OSA, those with risk of OSA were significantly more likely to have hypertension or cardiovascular disease and diabetes, had significantly higher body mass index and COPD Assessment Test scores, and reported impaired work performance and leisure activities.

Conclusion: Among adults in Taiwan who fulfill epidemiologic criteria for COPD, 29.5\% have coexisting risk of OSA. Comorbid hypertension or cardiovascular disease and diabetes are common and significantly more prevalent among the COPD population at risk of OSA than those who are not. OSA screening is warranted in patients with COPD with those risk factors that are more prevalent in COPD with risk of OSA than without, to target early interventions to reduce adverse cardiovascular sequelae from overlap syndrome.

Keywords: cardiovascular risk, COPD, coexistent, obstructive sleep apnea, OSA, overlap syndrome

\section{Introduction}

COPD is a lung disease characterized by persistently poor airflow consequent to irreparable disintegration of lung tissue and small airways dysfunction. The cardinal symptoms include shortness of breath, cough, and excess sputum production, which typically deteriorate over time. ${ }^{1}$ A substantial proportion of patients with COPD have comorbidities that significantly worsen prognosis, ${ }^{2}$ in particular due to morbidity and mortality from associated hypertensive and heart diseases. ${ }^{3,4}$ COPD is the third-ranking cause of death worldwide. ${ }^{5}$ Reported estimates of COPD prevalence among adults older than 40 years range from $4.0 \%$ to $20.0 \%$, with considerable variation due to differing methodologies, diagnostic definitions, and demographic characteristics. ${ }^{6,7}$ COPD is a leading and 
increasingly important cause of death in Taiwan; ${ }^{8}$ the average annual prevalence of chronic airway obstruction among adults aged 40 years and older was $2.48 \%$ from 1996 to $2002 .{ }^{9}$

Obstructive sleep apnea (OSA) is a common sleep disorder characterized by repetitive closure of the upper airway. OSA shares pathogenic processes of airway inflammation and obstruction and cardiovascular sequelae in common with COPD, and is similarly associated with cardiovascular morbidity and mortality. ${ }^{10,11}$ Reported estimates of OSA prevalence vary, but a commonly accepted figure is $\sim 5.0 \%$ among adults in developed countries. ${ }^{12,13}$ The prevalence of witnessed sleep apnea among Taiwanese adults ( $\geq 15$ years) was $2.6 \%$ in $2005 .{ }^{14}$

Coexistence of OSA in COPD as a distinct clinical syndrome was first propounded by Flenley, ${ }^{15}$ who coined the term "overlap syndrome" by which this is commonly known. There have been no large epidemiological studies of overlap syndrome, and reported prevalence estimates vary widely, from $1.0 \%$ up to nearly $30.0 \%,{ }^{16-18}$ in part reflecting differences between studies in the health status of the study cohorts and definitions of COPD and OSA. Several estimates cluster midway in this range, ${ }^{16,17}$ but the actual figure remains uncertain, as does whether the association between COPD and OSA reflects a genuine pathophysiological link, or is just coincidental. ${ }^{12,17-19}$

Notwithstanding the epidemiological uncertainties, it is evident that patients with coexisting COPD and OSA have higher morbidity and mortality compared with either condition in isolation..$^{20,21}$ Early diagnosis of patients with overlap syndrome is important because effective treatment is associated with reduced cardiovascular mortality. ${ }^{21,22}$ Therefore, diagnostic sleep studies, specifically polysomnography, are recommended to confirm suspected OSA in those patients with COPD with indicative symptoms such as heavy snoring, disturbed sleep, and/or daytime sleepiness; however, available evidence does not support polysomnography for other patients with COPD. ${ }^{23-26}$

To clarify uncertainties about the epidemiology of overlap syndrome and study potential indications for sleep apnea screening in COPD, we conducted a national survey with the primary objective of determining the frequency at which COPD coexists with risk of OSA symptoms in Taiwan. We further compared the risk factors, COPD symptoms, and life quality metrics of COPD subgroups with or without risk of OSA.

\section{Methods}

\section{Study design and sample selection}

We used a computer-assisted telephone interviewing system to conduct a random, population-based, cross-sectional survey of adults $>40$ years old residing in cities/counties/regions throughout Taiwan. The systematic sampling technique used national telephone number records. To constitute a representative national sample, the latest population statistics published by the Taiwan (Republic of China) Ministry of the Interior ${ }^{27}$ were used to restrict demographic data to quotas for age group, sex, and area/county/city of residence. Trained interviewers made calls from January 19 to May 8, 2013, to establish potential household contacts.

Participation was voluntary, and contacted individuals gave verbal informed consent before the interview and were free to withdraw at any stage. To protect participants' anonymity and confidentiality, all identifying data were delinked before analysis. This study was exempted from Institutional Review Board approval as per the Taiwan Food \& Drug Administration announcement, No. 1010265075, as the participants did not meet specified criteria for subjects mandating such review, were subjected to no medical interactions or interventions as a result of the study, and cannot be recognized individually from the data published.

Successful initial contacts were filtered against exclusion criteria: age $<40$ years; exceed demographic quota(s); prior interview/meeting relating to health care, market research, or advertising; and occupation of any domicile resident in advertising/market research/news media/public relations, or production/distribution/retail of medical or health care products.

\section{Respiratory health questionnaire}

Eligible contacts were asked five screening questions about COPD and respiratory symptoms to identify those with either diagnosed COPD or related respiratory symptoms (breathlessness, ongoing cough, cough with sputum, wheezing, and chest tightness) of $>3$ months duration that also fulfill an epidemiological case definition of COPD. These COPD cohorts were invited to complete the full 22-question survey. In addition to eliciting basic information about age, marital status, education level, specific occupations potentially hazardous to respiratory health, leisure activities, and smoking behavior, the survey form included a modified Medical Research Council (mMRC) Breathlessness Scale, ${ }^{28}$ COPD Assessment Test (CAT) including sleep quality, ${ }^{29}$ questions on height, weight, comorbid diseases (hypertension or cardiovascular disease, diabetes, stroke, cancer, tuberculosis), and performance of daily-living and occupational activities. The survey also incorporated a modified version of the Berlin Questionnaire, ${ }^{30}$ which is used to screen patients for likely OSA and includes questions on frequency and severity of snoring and severity of daytime fatigue and drowsiness. Body mass index (BMI) was calculated from subjects' reported weight and height. We defined 
the risk of OSA symptoms according to the modified Berlin criteria, as satisfying two from three possible qualifications: snoring $\geq 3-4$ times/wk and/or daytime sleepiness $\geq 3-4$ times/wk, with or without BMI $\geq 30 \mathrm{~kg} / \mathrm{m}^{2}$ or hypertensive cardiovascular disease.

\section{Statistical analysis}

Standard statistical approaches were used to derive the frequencies, percentages, mean, median, and standard deviations of descriptive demographic variables (age, sex, smoking, occupation, comorbidities, etc). Between-group proportions for dichotomous discrete outcomes, such as comorbidities, were compared using a two-sample difference of proportions test. Two-sample $t$-test was applied for continuous outcomes. Stepwise logistic regression using the forward selection method (dependent variables: $0=$ patients with COPD without risk of
OSA symptoms; $1=$ patients with COPD with risk of OSA symptoms) was performed to assess the likelihood of the risk of OSA versus no risk of OSA in subjects with COPD in the presence of exposure variables that included age, BMI, hypertension or cardiovascular disease, and CAT score. Data were collected, entered, and managed using IBM SPSS Data Collection Version 6.0. Statistical analyses were performed using IBM SPSS Statistics Version 19. All tests were twosided. $P$-value $<0.05$ was considered statistically significant.

\section{Results Frequencies of COPD and risk of OSA symptoms in the screening population}

The computer-assisted telephone interviewing system generated 195,212 telephone numbers that yielded 32,381 successful contacts (Figure 1). Of these, 6,600 from 17,949 that fulfilled

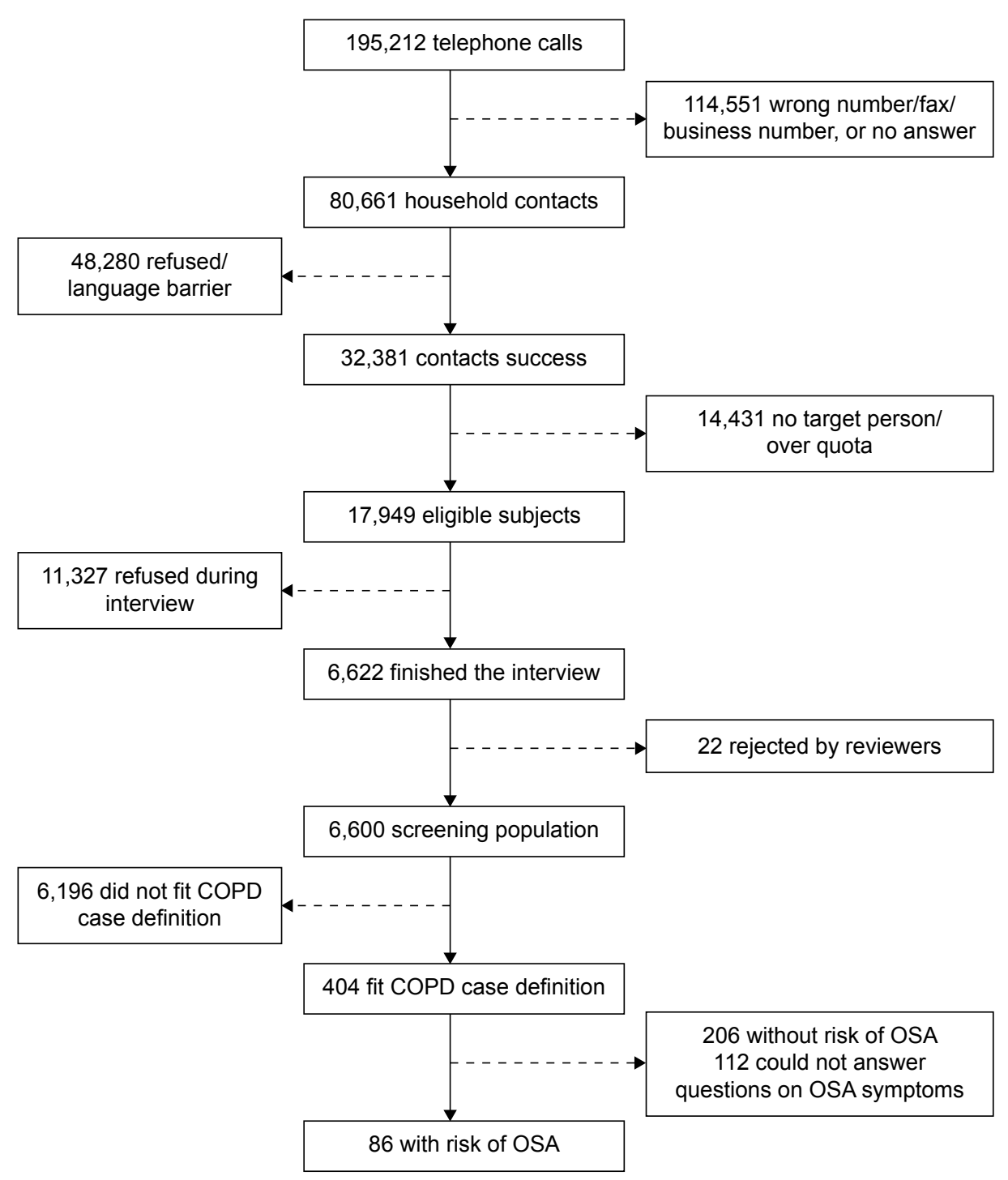

Figure I Subject flow for the pooled COPD population with risk of obstructive sleep apnea symptoms. Abbreviation: OSA, obstructive sleep apnea. 
the eligibility criteria were adjudged to have satisfactorily completed the interview - a response rate of $36.8 \%$. Among this national population sample, 404 (6.1\%) subjects either had clinically diagnosed COPD or fitted the epidemiological case definition. Data to assess the risk of OSA were available for 292 of this COPD cohort, of whom 86 (29.5\%) fulfilled the modified Berlin criteria for risk of OSA and 206 (70.5\%) did not have risk of OSA; the remaining 112 did not answer the questions used to assess OSA risk. Accordingly, COPD and risk of OSA symptoms, as defined in this study, coexisted at a frequency of at least $1.3 \%$ in the population screened.

\section{Demographic characteristics and} differences between COPD cohorts with or without risk of OSA symptoms

Subjects in the COPD cohort were predominantly male $(80.1 \%)$ and ever-smokers $(86.0 \%)$; these proportions were similar irrespective of OSA risk status, as were their median ages, age strata, and specified occupations potentially hazardous to respiratory health (Table 1). The COPD group at risk of OSA symptoms had significantly higher BMI than those without risk of OSA symptoms $(26.1 \pm 5.82 \mathrm{~kg} /$ $\mathrm{m}^{2}$ vs $\left.23.5 \pm 2.99 \mathrm{~kg} / \mathrm{m}^{2} ; P<0.001\right)$ and were significantly more likely to have hypertension or cardiovascular disease $(74.4 \%$ vs $26.7 \% ; P<0.001)$ and/or diabetes mellitus (23.3\% vs $8.3 \% ; P<0.001)$. Correspondingly, those without risk of OSA symptoms were comparatively less likely to have any of the specified comorbidities (65.5\% vs $22.1 \%$; $P<0.001)$.

\section{Symptomatic differences between COPD cohorts with or without risk of OSA symptoms}

mMRC Breathlessness scores did not differ significantly between the groups with or without risk of OSA symptoms (Table 2). However, the COPD cohort with risk of OSA

Table I Demographics of COPD cohort and comparison by risk of OSA symptoms status

\begin{tabular}{|c|c|c|c|c|}
\hline \multirow[t]{4}{*}{ Categories } & \multicolumn{3}{|c|}{ Subject data values and proportions (\%) } & \multirow{4}{*}{$\begin{array}{l}P \text {-value } \\
\text { (with risk of OSA } \\
\text { symptoms vs without) }\end{array}$} \\
\hline & \multirow{3}{*}{$\begin{array}{l}\text { COPD cohort }^{\mathrm{a}} \\
\overline{292(100)}\end{array}$} & \multicolumn{2}{|c|}{ OSA symptoms risk status } & \\
\hline & & \multirow{2}{*}{$\frac{\text { With }}{86(29.5)}$} & \multirow{2}{*}{$\frac{\text { Without }}{206(70.5)}$} & \\
\hline & & & & \\
\hline Median age (years) & 52.9 & 53.0 & 52.9 & $0.976^{\mathrm{b}}$ \\
\hline Ist-3rd quartile (IQR) & $44.9-66.2(17.3)$ & $44.8-62.0(17.2)$ & $45.0-62.3(17.3)$ & \\
\hline Age group (years) & & & & $0.842^{c}$ \\
\hline $40-45$ & $79(27.1)$ & $27(31.4)$ & $52(25.2)$ & \\
\hline $46-50$ & $50(17.1)$ & $12(14.0)$ & $38(18.4)$ & \\
\hline $51-55$ & $37(12.7)$ & $10(11.6)$ & $27(13.1)$ & \\
\hline $56-60$ & $45(15.4)$ & $13(15.1)$ & $32(15.5)$ & \\
\hline $6 \mathrm{I}-65$ & $19(6.5)$ & $7(8.1)$ & $12(5.8)$ & \\
\hline $66-70$ & $18(6.2)$ & $6(7.0)$ & $12(5.8)$ & \\
\hline$\geq 71$ & $44(15.1)$ & II (I2.8) & $33(16.0)$ & \\
\hline Sex & & & & $0.728^{c}$ \\
\hline Male & $234(80.1)$ & $70(81.1)$ & $164(79.6)$ & \\
\hline Female & $58(19.9)$ & $16(18.6)$ & $42(20.4)$ & \\
\hline Ever-smoker & $251(86.0)$ & $76(88.4)$ & $175(85.0)$ & $0.443^{c}$ \\
\hline Specified occupations ${ }^{d}$ & $106(36.3)$ & $32(37.2)$ & $74(35.9)$ & $0.835^{c}$ \\
\hline Body mass index $\left(\mathrm{kg} / \mathrm{m}^{2}\right)^{\mathrm{e}}$ & $24.3 \pm 4.19$ & $26.1 \pm 5.82$ & $23.5 \pm 2.99$ & $<0.00 \mathrm{I}^{\mathrm{c}}$ \\
\hline \multicolumn{5}{|l|}{ Comorbid diseases } \\
\hline $\begin{array}{l}\text { Hypertensive or } \\
\text { cardiovascular }\end{array}$ & $119(40.8)$ & $64(74.4)$ & $55(26.7)$ & $<0.00 \mathrm{I}^{\mathrm{c}}$ \\
\hline Stroke & $3(1.0)$ & $2(2.3)$ & I (0.5) & $0.208^{c}$ \\
\hline Diabetes mellitus & $37(12.7)$ & $20(23.3)$ & $17(8.3)$ & $<0.00 \mathrm{I}^{\mathrm{c}}$ \\
\hline Cancer & $10(3.4)$ & $4(4.7)$ & $6(2.9)$ & $0.457^{c}$ \\
\hline Tuberculosis & $10(3.4)$ & $\mathrm{I}(1.2)$ & $9(4.4)$ & $0.290^{c}$ \\
\hline None of the above & $154(52.7)$ & $19(22.1)$ & $135(65.5)$ & $<0.00 \mathrm{I}^{\mathrm{c}}$ \\
\hline
\end{tabular}

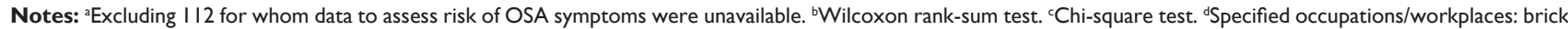
or ceramic factory, gravel pit, mine; textiles; building and decorating; chemical raw plant or dye factory; truck driver; baker; fire-fighter; cook with wood, coal, or briquettes. ${ }^{e}$ Calculated from self-reported weight and height.

Abbreviations: OSA, obstructive sleep apnea; IQR, interquartile range. 
Table 2 Symptomatic differences between COPD cohorts with or without risk of OSA symptoms

\begin{tabular}{llll}
\hline \multirow{2}{*}{$\begin{array}{l}\text { Symptoms/disability } \\
\text { quantification indices }\end{array}$} & \multicolumn{2}{l}{$\begin{array}{l}\text { OSA symptoms } \\
\text { risk status }\end{array}$} & \\
\cline { 2 - 3 } & With & Without & \\
\hline mMRC Breathlessness score & $0.9 \pm 1.03$ & $0.7 \pm 0.94$ & 0.261 \\
CAT score & $16.8 \pm 7.74$ & $12.7 \pm 7.10$ & $<0.001$ \\
Severity of cough & $2.5 \pm 1.46$ & $2.0 \pm 1.33$ & 0.022 \\
Amount of chest sputum & $2.1 \pm 1.48$ & $1.9 \pm 1.40$ & 0.266 \\
Degree of chest tightness & $1.8 \pm 1.38$ & $1.5 \pm 1.45$ & 0.186 \\
Breathing difficulty climbing stairs & $2.9 \pm 1.39$ & $2.3 \pm 1.38$ & $<0.001$ \\
Restriction of domestic activities & $1.3 \pm 1.55$ & $0.8 \pm 1.38$ & 0.006 \\
Confidence to go out & $1.3 \pm 1.66$ & $0.8 \pm 1.34$ & 0.013 \\
Quality of sleep & $2.3 \pm 1.80$ & $1.6 \pm 1.70$ & 0.002 \\
Daily vitality & $2.6 \pm 1.39$ & $1.9 \pm 1.39$ & $<0.001$ \\
\hline
\end{tabular}

Note: Independent-sample $t$-test.

Abbreviations: OSA, obstructive sleep apnea; mMRC, modified Medical Research Council; CAT, COPD Assessment Test.

symptoms had significantly higher total CAT scores than those without $(16.8 \pm 7.74$ vs $12.7 \pm 7.10 ; P<0.001)$. Significantly higher scores on individual CAT items indicated that, compared to those without risk of OSA symptoms, the COPD cohort with risk of OSA symptoms reported worse cough, experienced more difficulty breathing when climbing stairs, were more restricted in their domestic activities and less confident to go out, did not sleep as well, and felt less energetic (Table 2).

\section{Difference in life quality metrics between COPD cohorts with or without risk of OSA symptoms}

Questions relating to quality of life included the extent to which respiratory symptoms affected work performance and absence, leisure activities, and social interactions. Although the COPD cohort with risk of OSA symptoms took no more days-off sick than those without (Table 3), they reported that their respiratory symptoms significantly

Table 3 Life quality differences between COPD cohorts with or without risk of OSA symptoms

\begin{tabular}{llll}
\hline Life quality metrics & \multicolumn{2}{l}{$\begin{array}{l}\text { OSA symptoms risk } \\
\text { status }\end{array}$} & \multirow{2}{*}{ P-value $^{\text {a }}$} \\
\cline { 2 - 3 } & With & Without & \\
\hline Impaired work performance & $\mathrm{I} .5 \pm \mathrm{I} .52$ & $0.8 \pm \mathrm{I} .34$ & 0.002 \\
Work days absent due to & $\mathrm{I} .2 \pm 4.45$ & $\mathrm{I} . \mathrm{I} \pm 8.66$ & 0.955 \\
respiratory symptoms & & & \\
Impaired leisure activities & $\mathrm{I} .3 \pm \mathrm{I} .60$ & $0.5 \pm \mathrm{I} .08$ & $<0.00 \mathrm{I}$ \\
Impaired social interaction & $\mathrm{I} .0 \pm \mathrm{I} .52$ & $0.5 \pm \mathrm{I} . \mathrm{I} 2$ & 0.004 \\
\hline
\end{tabular}

Note: alndependent-sample $t$-test.

Abbreviation: OSA, obstructive sleep apnea. impaired work performance ( $1.5 \pm 1.52$ vs $0.8 \pm 1.34, P=0.002)$ and their leisure activities $(1.3 \pm 1.60$ vs $0.5 \pm 1.08 ; P<0.001)$ and social interactions $(1.0 \pm 1.52$ vs $0.5 \pm 1.12 ; P=0.004)$.

Multivariate analyses (Table S1 and S2) showed significant correlations between CAT score $(P=0.007)$ and having more than two comorbidities $(P=0.039)$, with impaired work performance; two or more comorbidities $(P=0.001)$, emergency room (ER) admission $(P=0.022)$, and hospitalization $(P=0.015)$, with work day absence due to respiratory symptoms; CAT $(P<0.001)$ and ER admission $(P=0.035)$, with impaired leisure activities; and CAT $(P=0.017)$, with impaired social interaction. Other factors, such as BMI, mMRC Breathlessness score, or intensive care unit admission did not correlate with life quality metrics. One Berlin Questionnaire item, fatigue upon waking, significantly correlated with impaired work performance $(P=0.014)$ and impaired social interaction $(P=0.012)$, whereas there was no significant correlation between daytime sleepiness and any of the life quality metrics $(P>0.1)$; however, falling asleep while driving did correlate with impaired leisure activities $(P=0.006)$ and impaired social interaction $(P=0.01)$.

\section{Independent predictors for the risk of OSA symptoms in COPD}

Hypertension and/or cardiovascular disease were the strongest predictors of the risk of OSA in COPD (Table 4), being 13.70 times more likely in COPD subjects with risk of OSA than without (95\% confidence interval [CI] 5.47-34.336; $P<0.001$ ). BMI (odds ratio $1.17 ; 95 \% \mathrm{CI}$ $1.06-1.30 ; P=0.003$ ) and CAT score (odds ratio $1.13 ; 95 \%$ CI 1.07-1.20; $P<0.001)$ were also positively associated with the risk of OSA. The association between age and OSA risk in this COPD cohort was negative. Although there was no statistical difference in age between the subjects who did or did not answer Berlin Questionnaire items (Table S4), there

Table 4 Independent predictors for risk of OSA symptoms ${ }^{\mathrm{a}}$ in COPD

\begin{tabular}{lll}
\hline Risk predictor & Odds ratio & P-value \\
\cline { 2 - 2 } & (95\% confidence interval) & \\
\hline Age & $0.944(0.905-0.983)$ & 0.006 \\
Body mass index & $1.173(1.057-1.302)$ & 0.003 \\
$\begin{array}{l}\text { Hypertension or } \\
\text { cardiovascular disease }\end{array}$ & $13.704(5.466-34.359)$ & $<0.00 \mathrm{I}$ \\
CAT score & $\mathrm{I} .134(\mathrm{I} .068-\mathrm{I} .204)$ & \\
\hline
\end{tabular}

Notes: aStepwise logistic regression using the forward selection method (dependent variables: $0=$ patients with COPD without risk of OSA symptoms; $I=$ patients with COPD with risk of OSA symptoms).

Abbreviations: OSA, obstructive sleep apnea; CAT, COPD Assessment Test. 
was a trend toward a higher incompletion rate in those older versus younger than 60 years $(34.1 \%$ vs $24.9 \%$; $P=0.054)$.

\section{Discussion}

This national survey reveals interesting new insights into the epidemiology of obstructive respiratory illnesses in Taiwan. A substantial proportion of subjects with COPD have coexisting risk of OSA and associated comorbidities. These findings have important implications for clinical practice in screening and treating patients with COPD.

\section{Study limitations and strengths}

While we took measures to ensure a representative sample, a major limitation of our study was that the response rate was lower than that generally regarded as desirable to negate the effect of sample bias. ${ }^{31}$ In particular, screening questions about respiratory health might possibly lead a disproportionate number of eligible contacts without such symptoms to withdraw prematurely, resulting in overrepresentation of respiratory symptoms among the screening population. Basing definitions of COPD and OSA risk on respondentreported symptoms rather than clinical diagnoses may also inflate prevalence compared with epidemiologic studies based on National Insurance records, since cases of asthma or cardiovascular disease may have been included; but on the other hand, this may reveal genuinely undiagnosed COPD. A major limitation was that OSA symptoms were neither clinically diagnosed nor confirmed by polysomnography. The Berlin Questionnaire only screens for OSA risk, is validated only for patients in primary care,${ }^{30}$ and has moderate sensitivity and specificity in Chinese patients, with limited screening value. ${ }^{32}$ Another limitation of this telephone survey was that quality of life was not assessed using a validated questionnaire, in interests of avoiding an overly lengthy interview. Lastly, data on the risk of OSA symptoms were unavailable for 112 of $404(27.7 \%)$ survey respondents in the COPD cohort who did not complete the Berlin Questionnaire items - they included some who declined to answer and others for undocumented reasons. Despite these limitations associated with a telephone survey, it also had the advantages of avoiding potential biases inherent in studying patient cohorts and providing real-life information on 6,600 members of the general adult population. Reported epidemiological data on COPD, OSA, and overlap syndrome derive from predominantly Caucasian populations. Ours are the first large-scale data from Asia specifically focused on these respiratory illnesses and as such constitute a valuable resource for reference and comparison.

\section{Epidemiology of COPD and OSA}

The prevalence of COPD in adults $>40$ years in Taiwan was $6.1 \%$, which lies toward the lower end of the range reported in international studies. ${ }^{6,7}$ In a population cohort based on National Health Insurance claims from 1996 to 2002, the prevalence of chronic airway obstruction in adults older than 40 was $2.48 \%,{ }^{9}$ which is substantially less than most international estimates. While our figure might be an overestimate if respiratory patients were overrepresented in our sampling population, it may truly indicate a substantial hidden burden of undiagnosed COPD in Taiwan. Indeed, another recent survey of COPD in Asia-Pacific estimated the prevalence among 207 Taiwanese subjects to be $9.5 \%{ }^{33}$

Studies to date have produced conflicting findings on the coexistence of OSA in COPD and the nature of the association between them, with comparisons confounded by sampling processes and definitions. ${ }^{19}$ Swedish investigators have reported OSA to be twice as common in subjects with chronic bronchitis as in those without pulmonary disease or symptoms. ${ }^{34}$ In contrast, the Sleep Heart Health Study, which has been the largest investigation to date, found OSA to be no more common in obstructive airway disease than in the general population; at respiratory disturbance index thresholds of 10 and 15, respective prevalence of OSA was $22.3 \%$ and $14.0 \%$ in subjects with obstructive airway disease and $28.9 \%$ and $18.6 \%$ in those without. ${ }^{18}$ Due to limitations of these and other reported studies, in particular, underrepresentation of severe COPD, the true prevalence of overlap syndrome remains controversial. ${ }^{12}$

In our survey, $29.5 \%$ of subjects fitting the epidemiological case description for COPD had coexisting risk of OSA symptoms. Although this lies at the upper end of the range of most reported estimates of overlap syndrome, ${ }^{16,17}$ that may be expected given our relatively broad definitions of each condition compared with stricter clinical diagnostic criteria. In particular, the Berlin Questionnaire is only a screening tool to identify patients with OSA symptoms; besides genuine cases of OSA, this population might also include upper airway resistance syndrome, nocturnal desaturated patients without OSA, and asthma-related conditions, which would lead to an overestimate of the prevalence of OSA in COPD. It may also reflect the predominance of males and ever-smokers in our COPD cohort. Both COPD and OSA occur more commonly in males than females, ${ }^{7,13}$ and tobacco smoking is known to predispose to $\mathrm{COPD}^{35}$ and may also be a risk factor for OSA. ${ }^{36}$

Despite previous reports that older age is an important risk factor for OSA, ${ }^{37,38}$ our analysis showed that advanced 
age among members of the COPD cohort was associated with reduced risk of OSA symptoms. This observation may be an artifact of the study methodology as older respondents were more likely to decline to answer further questions after completing the main part of the survey (Table S4).

Based on the Sleep Heart Health Study, several commentators concur that since both COPD and OSA are relatively common, their coexistence is likely coincidental and would be expected by chance at a frequency of $0.5 \%-1.0 \%$ in adults $>40$ years (based on respective prevalence of $\sim 10 \%$ and $\sim 5 \%-10 \%) .{ }^{16,17,19}$ COPD and risk of OSA symptoms, as defined in our study, coexisted at a frequency of $1.3 \%$ in the general population, which does not appear to be a very dissimilar proportion, especially if subjects with either condition were overrepresented. While the limitations and uncertainties of our study and others preclude firm conclusion about the prevalence of COPD, OSA, and overlap syndrome, there is no indication from our results that overlap syndrome is any less of a problem in Taiwan than elsewhere.

\section{Poorer health and life quality when COPD coexists with OSA}

Compared with COPD subjects without coexisting risk of OSA in our survey, those with the risk of OSA had more symptomatic COPD, more comorbid illness, slept worse, and reported greater interference of respiratory symptoms in their social and working lives.

Both COPD and OSA are associated with increased risk of cardiovascular morbidity and mortality; $;^{4,11,39}$ however, these relationships and the underlying mechanisms are not entirely understood. ${ }^{40}$ In the ECLIPSE study, patients with more symptomatic COPD and cardiac comorbidities but fewer risk factors, had similarly poor clinical outcomes and mortality as those with fewer symptoms but more risk factors. ${ }^{41}$ In a multivariate analysis of 10,981 patients with sleep apnea, all-cause mortality was most strongly associated with COPD, and mortality associated with OSA was significantly increased in the presence of COPD. ${ }^{42}$ The significant associations we observed between comorbid hypertension/ cardiovascular disease and diabetes mellitus with the risk of OSA symptoms may reflect common inflammatory and cardiovascular sequelae of airway obstruction in COPD and OSA. ${ }^{39,40,43,44}$ There is an evidence for a positive correlation between systemic inflammation and impaired lung function, ${ }^{45}$ and patients with OSA also have elevated levels of inflammatory mediators, particularly those associated with cardiovascular risk, such as nuclear factor kappa $\mathrm{B},{ }^{46}$ tumor necrosis factor, interleukin-6, C-reactive protein, ${ }^{47}$ and homocysteine. ${ }^{48}$

In general, our findings are consistent with the proposition that coexisting OSA may contribute to worsening COPD and be associated with increased risk of hypertensive cardiovascular disease. However, it remains unclear whether the inflammatory consequences of COPD and OSA in overlap syndrome are additive or synergistic; further studies are, therefore, needed to investigate whether their relationship is causative or correlative.

Our findings also accord with the few published reports on sleep and quality of life in patients with COPD and/or OSA. Disrupted sleep is a hallmark of OSA, particularly in more symptomatic individuals, and many patients consequently suffer from insomnia. ${ }^{49}$ Insomnia is also more common in subjects with respiratory symptoms of cough and/ or wheezing than those without. ${ }^{50}$ Sleep Heart Health Study patients with overlap syndrome had less efficient and more perturbed sleep than those with either OSA or obstructive airway disease alone. ${ }^{18}$ In a single study, patients with overlap syndrome had significantly higher scores than those with COPD alone on scales of symptoms, activity, and impacts, indicating markedly impaired quality of life. ${ }^{51}$ Although we observed no direct effect of snoring or disrupted breathing during sleep on life quality metrics, fatigue upon waking and drowsiness while driving did correlate with some aspects, which may account for differences in life quality between the COPD cohorts with versus without risk of OSA symptoms. Likewise, our findings support the contention that symptoms that contribute to the risk of OSA, such as snoring, daytime sleeping, and poor sleep quality, may also explain the elevated scores we observed on individual CAT items.

\section{Rationale for early diagnosis and treatment to reduce adverse cardiovascular sequelae from overlap syndrome}

Worsened prognosis in overlap syndrome than for either COPD or OSA alone may be principally attributed to increased frequency and overall duration of hypoxemic episodes, which result in repeated transient elevations of pulmonary arterial pressure that foment the development of pulmonary hypertension and right heart failure. ${ }^{21,23}$ Accordingly, effective OSA treatment with continuous positive airway pressure has been shown to improve survival, largely due to reduced cardiovascular mortality, and decrease hospitalizations for exacerbations of COPD. ${ }^{20-22}$ Therefore, although routine polysomnography is unlikely to detect clinically important unsuspected OSA among patients with COPD at higher rates 
than in the general population, ${ }^{23}$ clinical sleep studies should be performed to screen patients with COPD with suspected OSA, which is indicated by characteristics such as snoring, disturbed sleep, and/or daytime sleepiness. ${ }^{23-26}$

\section{Conclusion}

A substantial proportion of adults in Taiwan who fulfill the epidemiologic criteria for COPD also have symptoms associated with OSA. These findings suggest that COPD with coexisting OSA may be as common in Taiwan as elsewhere, and affirm that it is associated with worse symptoms than COPD alone, higher likelihood of comorbid diseases, and poorer quality of life. It is important to diagnose patients with overlap syndrome early because they are at especially high risk of cardiovascular mortality, and effective pre-emptive treatment improves survival. Hypertensive or cardiovascular disease, obesity, and high CAT scores predict the risk of OSA symptoms in COPD. OSA screening is therefore warranted in patients with COPD with these risk factors, especially hypertensive or cardiovascular comorbidities, in order to target early interventions to reduce the risk of adverse sequelae from overlap syndrome.

\section{Acknowledgments}

This study was supported financially by Takeda Pharmaceuticals Taiwan, Ltd. However, the sponsor had no role in the study design, data collection or analysis, or the decision to publish. Takeda staff reviewed early drafts of the manuscript, but the authors were independent in deciding whether to incorporate feedback and approving the final revised version. Dr David Neil (PhD), of Content Ed Net Taiwan Limited, provided medical writing services, which were remunerated by Takeda.

\section{Disclosure}

The authors report no conflicts of interest in this work.

\section{References}

1. Global Initiative for Chronic Obstructive Lung Disease (GOLD) [webpage on the Internet]. Global Strategy for the Diagnosis, Management, and Prevention of Chronic Obstructive Pulmonary Disease. [Guidelines on the internet]. Updated February 2013. [cited September 9, 2015]. Available from: www.goldcopd.org/uploads/users/files/GOLD_ Report_2013_Feb20.pdf. Accessed September 9, 2015.

2. Chatila WM, Thomashow BM, Minai OA, Criner GJ, Make BJ. Comorbidities in chronic obstructive pulmonary disease. Proc Am Thorac Soc. 2008;5:549-555.

3. Müllerova H, Agusti A, Erqou S, Mapel DW. Cardiovascular comorbidity in COPD: systematic literature review. Chest. 2013;144:1163-1178.

4. Sin DD, Man SF. Chronic obstructive pulmonary disease as a risk factor for cardiovascular morbidity and mortality. Proc Am Thorac Soc. 2005; $2: 8-11$.
5. World Health Organization [webpage on the Internet]. Fact sheet № 310. Updated May 2014. The 10 Leading Causes of Death in the World, 2000 and 2012. [cited September 9, 2015]. Available from: http://www.who. int/mediacentre/factsheets/fs310/en/. Accessed September 9, 2015.

6. Hsu JH, Chien IC, Lin $\mathrm{CH}$, Chou YJ, Chou P. Increased risk of chronic obstructive pulmonary disease in patients with schizophrenia: a population-based study. Psychosomatics. 2013;54:345-351.

7. Buist AS, McBurnie MA, Vollmer WM, et al; BOLD Collaborative Research Group. International variation in the prevalence of COPD (the BOLD study): a population-based prevalence study. Lancet. 2007;370: 741-750.

8. Kuo LC, Yang PC, Kuo SH. Trends in the mortality of chronic obstructive pulmonary disease in Taiwan, 1981-2002. J Formos Med Assoc. 2005;104:89-93.

9. Wang YC, Lin JM, Li CY, Lee LT, Guo YL, Sung FC. Prevalence and risks of chronic airway obstruction: a population cohort study in Taiwan. Chest. 2007;131:705-710.

10. Young T, Palta M, Dempsey J, Skatrud J, Weber S, Badr S. The occurrence of sleep-disordered breathing among middle-aged adults. $N$ Engl J Med. 1993;328:1230-1235.

11. Yüksel P, Peker Y, Hedner J, Norum J, Kraiczi H, Carlson J. Increased incidence of cardiovascular disease in middle-aged men with obstructive sleep apnea: a 7-year follow-up. Am J Respir Crit Care Med. 2002;166: 159-165.

12. Hiestand D, Phillips B. The overlap syndrome: chronic obstructive pulmonary disease and obstructive sleep apnea. Crit Care Clin. 2008;24: 551-563.

13. Young T, Peppard PE, Gottlieb DJ. Epidemiology of obstructive sleep apnea: a population health perspective. Am J Respir Crit Care Med. 2002;165:1217-1239.

14. Chuang LP, Hsu SC, Lin SW, Ko WS, Chen NH, Tsai YH. Prevalence of snoring and witnessed apnea in Taiwanese adults. Chang Gung Med J. 2008:31:175-181.

15. Flenley DC. Sleep in chronic obstructive lung disease. Clin Chest Med. 1985;6:651-661.

16. McNicholas WT. Chronic obstructive pulmonary disease and obstructive sleep apnea: overlaps in pathophysiology, systemic inflammation, and cardiovascular disease. Am J Respir Crit Care Med. 2009;180: 692-700.

17. Zamarrón C, García Paz V, Morete E, del Campo Matías F. Association of chronic obstructive pulmonary disease and obstructive sleep apnea consequences. Int J Chron Obstruct Pulmon Dis. 2008;3:671-682.

18. Sanders MH, Newman AB, Haggerty CL, et al; Sleep Heart Health Study. Sleep and sleep-disordered breathing in adults with predominantly mild obstructive airway disease. Am J Respir Crit Care Med. 2003;167:7-14.

19. Weitzenblum E, Chaouat A, Kessler R, Canuet M. Overlap syndrome: obstructive sleep apnea in patients with chronic obstructive pulmonary disease. Proc Am Thorac Soc. 2008;5:237-241.

20. Chaouat A, Weitzenblum E, Krieger J, et al. Prognostic value of lung function and pulmonary haemodynamics in OSA patients treated with CPAP. Eur Respir J. 1999;13:1091-1096.

21. Marin JM, Soriano JB, Carrizo SJ, Boldova A, Celli BR. Outcomes in patients with chronic obstructive pulmonary disease and obstructive sleep apnea: the overlap syndrome. Am J Respir Crit Care Med. 2010;182:325-331.

22. Marin JM, Carrizo SJ, Vincente E, Agusti AG. Long-term cardiovascular outcomes in men with obstructive sleep apnoea-hypopnoea with or without treatment with continuous positive airway pressure: an observational study. Lancet. 2005;365:1046-1053.

23. Douglas NJ. Are sleep studies necessary in COPD? Lung. 1990; 168(suppl):943-947.

24. Chesson AL Jr, Ferber RA, Fry JM, et al. The indications for polysomnography and related procedures. Sleep. 1997;20:423-487.

25. Celli BR, MacNee W; ATS/ERS Task Force. Standards for the diagnosis and treatment of patients with COPD: a summary of the ATS/ ERS position paper. Eur Respir J. 2004;23:932-946. 
26. Kushida CA, Littner MR, Morgenthaler T, et al. Practice parameters for the indications for polysomnography and related procedures: an update for 2005. Sleep. 2005;28:499-521.

27. Republic of China (Taiwan), Ministry of Interior, Statistics Bureau [webpage on the Internet]. 2010 Population and Housing Census, Abstract Report. Available from: http://ebas1.ebas.gov.tw/phc2010/ english/51/a1.pdf. Accessed 9 September 2015.

28. Stenton C. The MRC breathlessness scale. Occup Med (Lond). 2008; 58:226-227.

29. Jones PW, Harding G, Berry P, Wiklund I, Chen WH, Kline Leidy N. Development and first validation of the COPD assessment test. Eur Respir J. 2009;34:648-654.

30. Netzer NC, Stoohs RA, Netzer CM, Clark K, Strohl KP. Using the Berlin questionnaire to identify patients at risk for the sleep apnea syndrome. Ann Intern Med. 1999;131:485-491.

31. Groves RM. Nonresponse rates and nonresponse bias in household surveys. Public Opin Q. 2006;70:646-675.

32. Lü XP, Zhang C, Ma J, et al. [Application of Berlin questionnaire in the screening of obstructive sleep apnea hypopnea syndrome]. Zhonghua Jie He He Hu Xi Za Zhi. 2011;34:515-519. Chinese.

33. Lim S, Lam DC, Muttalif AR, et al. Impact of chronic obstructive pulmonary disease (COPD) in the Asia-Pacific region: the EPIC Asia population-based survey. Asia Pac Fam Med. 1015;14:4.

34. Larsson LG, Lindberg A, Franklin KA, Lundbäck B; Obstructive Lung Disease in Northern Sweden Studies. Obstructive sleep apnoea syndrome is common in subjects with chronic bronchitis. Report from the obstructive lung disease in northern Sweden studies. Respiration. 2001;68:250-255.

35. Pauwels RA, Buist AS, Calverley PM, Jenkins CR, Hurd SS; GOLD Scientific Committee. Global strategy for the diagnosis, management, and prevention of chronic obstructive pulmonary disease. NHLBI/WHO global initiative for chronic obstructive lung disease (GOLD) workshop summary. Am J Respir Crit Care Med. 2001;163:1256-1276.

36. Kashyap R, Hock LM, Bowman TJ. Higher prevalence of smoking in patients diagnosed as having obstructive sleep apnea. Sleep Breath. 2001;5:167-172.

37. Bixler EO, Vgontzas AN, Ten Have T, Tyson K, Kales A. Effects of age on sleep apnea in men: I. Prevalence and severity. Am J Respir Crit Care Med. 1998;157:144-148.
38. Bixler EO, Vgontzas AN, Lin HM, et al. Prevalence of sleep-disordered breathing in women: effects of gender. Am J Respir Crit Care Med. 2001;163:608-613.

39. Calverley PM, Scott S. Is airway inflammation in chronic obstructive pulmonary disease (COPD) a risk factor for cardiovascular events? COPD. 2006;3:233-342.

40. Lavie L. Obstructive sleep apnoea syndrome-an oxidative stress disorder. Sleep Med Rev. 2003;7:35-51.

41. Agusti A, Edwards LD, Celli B, et al; ECLIPSE Investigators. Characteristics, stability and outcomes of the 2011 GOLD COPD groups in the ECLIPSE cohort. Eur Respir J. 2013;42:636-646.

42. Lavie P, Herer P, Lavie L. Mortality risk factors in sleep apnoea: a matched case-control study. J Sleep Res. 2007;16:128-134.

43. Kiely JL, McNicholas WT. Cardiovascular risk factors in patients with obstructive sleep apnoea syndrome. Eur Respir J. 2000;16:128-133.

44. Wouters EF. Local and systemic inflammation in chronic obstructive pulmonary disease. Proc Am Thorac Soc. 2005;2:26-33.

45. Walter RE, Wilk JB, Larson MG, et al. Systemic inflammation and COPD: the Framingham heart study. Chest. 2008;133:19-25.

46. Yamauchi M, Tamaki S, Tomoda K, et al. Evidence for activation of nuclear factor kappaB in obstructive sleep apnea. Sleep Breath. 2006;10:189-193.

47. Shamsuzzaman AS, Winnicki M, Lanfranchi P, et al. Elevated C-reactive protein in patients with obstructive sleep apnea. Circulation. 2002;105:2462-2464

48. Can M, Açikgöz S, Mungan G, et al. Serum cardiovascular risk factors in obstructive sleep apnea. Chest. 2006;129:233-237.

49. Valipour A, Lothaller H, Rauscher H, Zwick H, Burghuber OC, Lavie P. Gender-related differences in symptoms of patients with suspected breathing disorders in sleep: a clinical population study using the sleep disorders questionnaire. Sleep. 2007;30:312-319.

50. Klink ME, Dodge R, Quan SF. The relation of sleep complaints to respiratory symptoms in a general population. Chest. 1994;105:151-154.

51. Mermigkis C, Kopanakis A, Foldvary-Schaefer N, et al. Health-related quality of life in patients with obstructive sleep apnoea and chronic obstructive pulmonary disease (overlap syndrome). Int J Clin Pract. 2007;61:207-211
International Journal of COPD

\section{Publish your work in this journal}

The International Journal of COPD is an international, peer-reviewed journal of therapeutics and pharmacology focusing on concise rapid reporting of clinical studies and reviews in COPD. Special focus is given to the pathophysiological processes underlying the disease, intervention programs, patient focused education, and self management protocols.

\section{Dovepress}

This journal is indexed on PubMed Central, MedLine and CAS. The manuscript management system is completely online and includes a very quick and fair peer-review system, which is all easy to use. Visit http://www.dovepress.com/testimonials.php to read real quotes from published authors. 